Journal of Animal and Veterinary Advances 11 (16): 2865-2872, 2012

ISSN: $1680-5593$

(C) Medwell Journals, 2012

\title{
Factors Affecting the Derivation and Expansion of Bovine Embryonic Stem Cell-Like Cells
}

Rui Wang, Shan Cong, Ming Cang, Yuzhen Ma, Jianxun Wen and Dongjun Liu Key Laboratory of China for Mammal Reproduction Biology and Biotechnology, Ministry of Education, Inner Mongolia University, 010021 Hohhot, P.R. China

\begin{abstract}
Bovine ES cells have been isolated but validated bovine ES cell lines have not yet been successfully established. Here, researchers investigated the factors that affect the derivation, proliferation and maintenance of bovine Embryonic Cell (bESC)-like cells including type of feeders (Mouse Embryonic Fibroblasts (MEFs) vs. Bovine Embryonic Fibroblasts (BEFs)), feeder density and inner cell mass isolation procedure. We found that the MEFs work better than BEFs on the process and best at a cell density of $1.25 \times 10^{5}$ cells $/ \mathrm{cm}^{2}$, naturally hatched blastocysts had a short adherence time and high rate of adherence. They were more conducive to bESC-like cell isolation and culture. Culture medium supplemented with IGF promoted proliferation of bESC-like cells but was unfavorable for the maintenance of pluripotency. The findings provide information on the establishment of culture systems for bESC-like cells.
\end{abstract}

Key words: Bovine embryonic stem cell-like cells, MEF, feeder layer density, IGF, blastocysts

\section{INTRODUCTION}

Embryonic Stem (ES) cells are derived from pluripotent cells present in the inner cell mass of an embryo. The successful establishment of mouse ES cell lines (Evans and Kaufman, 1981) has led to the efforts in establishing similar cell lines in other animals including cattle. Bovine ES cells have been isolated but stable bovine ES cell lines have not yet been successfully established.

Saito et al. (2004) first isolated bovine ES Cell (bESC)like cells and cultured them $>4$ passages then these cells differentiated into epithelial-like cells, fibroblast-like cells and nerve-like cells. Sims and First (1994) obtained 15 stem cell lines by a low-density culture method they were differentiated into embryoid bodies and were used as nuclear donors to give birth to four normal calves. However, contraries to the situation in mice and primates, a key barrier to genetic modification in livestock has been the no practical approach established to have stable ES cell lines in cattle although, many efforts have been put on this (Gjorret and Maddox-Hyttel, 2005; Munoz et al., 2008; Roach et al., 2006; Cao et al., 2009).

Many different type cells including homologous and heterologous fetal fibroblasts have been tested to use as feeder cells during derivation and maintenance of ESCs. Homologous fetal fibroblasts have been successfully used as feeder cells to derive ESCs in the mink (Sukoyan et al., 1993), pig (Li et al., 2004) and humans (Mali et al., 2008). Homologous primary feeder cells would be expected to be a better choice since they produce homologous growth factors or cytokines to maintain ES pluripotency. To the knowledge, it is still not clear if Bovine Embryonic Fibroblasts (BEF) are more suitable than Mouse Embryonic Fibroblasts (MEF) as feeder cells for either the establishment or the maintenance of bESC in undifferentiated pluripotent state.

Also, it is believed that the density and quality of the feeder cells have great impact on the maintenance of ES pluripotency. The density of feeder layer shows a great influence on the culture of embryonic stem-like cells (Ozolek et al., 2007). The density of the feeder cell layer influenced the growth pattern of $\mathrm{hES}$ cell colonies. At a high feeder cell density, the $\mathrm{hES}$ colonies were more pointed and aligned with the direction of the fibroblasts whereas less dense feeder layers allowed a more rounded and flat $\mathrm{hES}$ colony formation. (Imreh et al., 2004).

IGF-I protein supports feeder-free and serum-free culture of human embryonic stem cells (Manton et al., 2010). It has widely been reported that basic Fibroblast Growth Factor (bFGF) promotes proliferation of human stem cells and contributes to the maintenance of their self-renewal capability through repeated replications (Park et al., 2009).

Corresponding Author: Dongjun Liu, Key Laboratory of China for Mammal Reproduction Biology and Biotechnology, Ministry of Education, Inner Mongolia University, 010021 Hohhot, P.R. China 
In this study, researchers investigated the factors that affect bESC-like cell growth including the types of feeders the cell density of feeders and Insulin-like Growth Factor (IGF). The information obtained will help in the establishment of bovine stem cell lines in the future.

\section{MATERIALS AND METHODS}

Reagents: High-glucose Dulbecco's Modified Eagle's Medium (DMEM), DMEM/F12, penicillin/streptomycin and Fetal Bovine Serum (FBS) were purchased from Gibco (Carlsbad, CA). FBS for ES cell culture was from Chemicon (Temecula, CA). Trypsin was from Hyclone (Logan, UT). Fibroblast Growth Factor-2 (bFGF) and Human IGF-I (hIGF-I) were from Promega (Madison, WI). Mouse Leukemia Inhibitory Factor (mLIF) and None-Essential Amino Acids (NEAA) were from Sigma (St. Louis, MO). $\beta$-Mercaptoethanol and ES cell marker sample kits were from Millipore (Bedford, MA). Mitomycin C was from Hisun Pharmaceutical Co. Ltd. (Zhejiang, China). All other chemicals were of analytical reagent grade.

Preparation of BEFs: Bovine fetuses at about 4-6 weeks of age were obtained from a local slaughterhouse. The heads, bones and abdominal organs of the fetuses were removed and the remaining tissues minced into $1 \mathrm{~mm}^{3}$ pieces. The tissue pellets were placed on $60 \mathrm{~mm}$ dishes (Corning Life Sciences, Corning, NY) and incubated for $10-30 \mathrm{~min}$ at $37^{\circ} \mathrm{C}$ under an atmosphere of $5 \% \mathrm{CO}_{2}$; $\mathrm{BEF}$ growth medium (Cell Applications, San Diego, CA) was then added for further culture. After 7 days of culture, BEFs were grown out from the tissue pieces. The cells were digested by $0.25 \%$ trypsin for subculture.

Preparation of MEFs: About 13 days olded mouse fetuses were dissected from uteri. After washing in Phosphate Buffered Saline (PBS), the heads, bones and abdominal organs of the fetuses were removed and the remaining tissues minced into $1 \mathrm{~mm}^{3}$ pieces. The tissue pellets were digested with $0.05 \%$ trypsin for $30 \mathrm{sec}$ by repeated pipetting. The trypsin disaggregate was neutralized with $1 \mathrm{~mL}$ of DMEM with $10 \%$ FBS. The suspension was then transferred to a conical centrifuge tube and large pieces of cellular debris were allowed to settle for $5 \mathrm{~min}$. The supernatant containing MEFs was transferred to $60 \mathrm{~mm}$ dishes and cultured at $37^{\circ} \mathrm{C}$ under an atmosphere of $5 \% \mathrm{CO}_{2}$. The medium was changed every 2 days and the cells were subcultured or stored in liquid nitrogen.

Feeder cell layer and cell density: For preparation of MEF and $\mathrm{BEF}$ feeder layers, fibroblasts were inactivated in a medium containing $30 \mathrm{ng} \mathrm{mL} \mathrm{m}^{-1}$ mitomycin-C. When the mitomycin-C treated cells had grown to $80-90 \%$ confluence, the cells were harvested by trypsinization. Cell suspensions of various densities $\left(2 \times 10^{4}, 1.25 \times 10^{5}\right.$ and $5 \times 10^{5}$ cells $/ \mathrm{cm}^{2}$ ) were seeded in 24 well plates precoated with $0.1 \%$ gelatin. The plates were incubated at $37^{\circ} \mathrm{C}$ under an atmosphere of $5 \% \mathrm{CO}_{2}$ overnight.

Embryo preparation and bESC-like cell culture: Oocytes were collected from cattle ovaries at an abattoir. Mature oocytes were fertilized in vitro as described previously (Rexroad and Powell, 1997). The zygotes were cultured in an in vitro production system using SOFaa medium supplemented with $10 \%$ FBS. The embryos were subjected to three different treatments: the zona pellucida was removed with $5 \mathrm{mg} \mathrm{mL}^{-1}$ pronase; hatching was allowed to proceed naturally or the Inner Cell Mass (ICM) of hatched embryos was disaggregated by a mechanical method. The treated embryos or ICMs were transferred into 24 well culture dishes coated with feeder layers. After 5-6 days, ICM-derived outgrowths were separated into clumps by mechanical dissociation with a micropipette and replated on mitomycin C-treated mouse or bovine embryonic fibroblasts in fresh medium. To passage the putative ES cells individual colonies with a uniform and undifferentiated morphology were selected individually using a micropipette, mechanically dissociated into two to six clumps and replated on prepared feeders. The ES cells were passaged every 3-5 days after replating. Researchers used three different media for culture: the difference between Solution 1 and 2 is their sources of FBS. Solution 3 was supplemented with IGF in the Solution 2. Solution 1 (DMEM/F12+15\% $\quad$ FBS+0.1 $\mathrm{mM} \quad \beta-$ mercaptoethanol $+0.1 \mathrm{mM}$ NEAA + penicillin/ streptomycin $+10 \mathrm{ng} \mathrm{mL}^{-1} \mathrm{LIF}+10 \mathrm{ng} \mathrm{mL} \mathrm{m}^{-1} \mathrm{bFGF}$ ); Solution $2(\mathrm{DMEM} / \mathrm{F} 12+15 \%$ FBS specifically for stem cells $+0.1 \mathrm{mM} \beta$-mercaptoethanol $+0.1 \mathrm{mM} \mathrm{NEAA}+$ penicillin/streptomycin $+10 \mathrm{ng} \mathrm{mL}{ }^{-1} \mathrm{LIF}+10 \mathrm{ng} \mathrm{mL}{ }^{-1}$ $\mathrm{bFGF}$ ) and Solution 3 (DMEM/F12 + 15\% FBS + $0.1 \mathrm{mM}$ $\beta$-mercaptoethanol $+0.1 \mathrm{mM} \mathrm{NEAA}+$ penicillin/ streptomycin $+10 \mathrm{ng} \mathrm{mL} \mathrm{mL}^{-1} \mathrm{LIF}+10 \mathrm{ng} \mathrm{mL} \mathrm{mFF}^{-1} \mathrm{bFGF}$ $+10 \mathrm{ng} \mathrm{mL}^{-1} \mathrm{IGF}$ ).

Alkaline phosphatase staining: Alkaline Phosphatase (AP) activity was detected as described previously (Roach et al., 2006). Briefly, bESC-like cells at different passages were fixed with $4 \%$ paraformaldehyde for $30 \mathrm{~min}$. Fixed cells were washed twice with PBS and stained with AP staining solution (Westang, Shanghai, China) according to the manufacturer's instructions. The cells were stained for $30 \mathrm{~min}$ in the dark and observed under a light microscope.

Immuno staining: bESC-like cells at the fifth passage grown on coverslips were washed and fixed with $4 \%$ paraformaldehyde. The cells were pretreated with $10 \%$ 
normal goat serum-PBS for $30 \mathrm{~min}$ then cell-surface Stage-Specific Embryonic Antigen (SSEA)-1 and 4 and expression of TRA-1-60 and Oct-4 were determined using a Millipore ES Cell Marker Sample kit according to the protocol supplied by the manufacturer. After incubation with fluorochrome conjugated secondary antibodies, immunofluorescent images were observed under a fluorescence microscope.

RT-PCR: Total RNA was isolated using RNAiso Plus (Takara, Dalian, China) from bESC-like cells at the fifth passage according to the manufacturer's instructions. RT-PCR was performed using a PrimeScript ${ }^{\circledR}$ RT reagent kit (Perfect Real Time) (Takara) following the protocol supplied with the kit. The following primers were used: Nanog sense 5'-GTCCCGGTCAAGAAACAAAA-3', antisense 5'-TCTGGAACCAGGTCTTCACC-3'; Oct-4 sense 5'-AGGTGTTCAGCCAAACGACTATC-3', antisense 5'-TCAGCTTCCTCCACCCACTTC-3'; Sox-2 sense 5'-CATGCACCGCTACGACGTGAG-3', antisense 5'CCTGGAGTGGGAAGAAGAGGTAAC-3'; GAPDHsense 5'-CAAGTTCAACGGCACAGTCA-3', antisense 5'CCACCACATACTCAGCACCAG- $3^{\prime}$. The PCR conditions were $94^{\circ} \mathrm{C}$ for $1 \mathrm{~min}$ to denature the RNA/cDNA hybrid then 30 cycles of $94^{\circ} \mathrm{C}$ for $1 \mathrm{~min}, 60^{\circ} \mathrm{C}$ for $30 \mathrm{sec}$ and $72^{\circ} \mathrm{C}$ for $30 \mathrm{sec}$ and a final extension at $72^{\circ} \mathrm{C}$ for $10 \mathrm{~min}$. PCR products were examined on a $1.5 \%$ agarose gel. The amplified products were confirmed under UV light after ethidium bromide staining. Researchers amplified GAPDH as an internal control.

\section{RESULTS AND DISCUSSION}

Effects of feeder cell layer on bESC-like cell growth: As feeder cells play very important roles in support ES growing. Researchers tested $\mathrm{BEF}$ and $\mathrm{MEF}$ feeder layers on the maintenance of bESC-like cells. The results showed that bESC-like cells grew faster on MEF layer than on $\mathrm{BEF}$ layer. ES cell colonies at the fifth passage on $\mathrm{BEF}$ layer were not tightly packed and there was some disaggregation. After the fifth passage, the colonies were no longer attached on BEF layer any more. On the other hand, ES cell colonies on MEFs were still kept as undifferentiated state at the 10th passage (Fig. 1) (Time). After passaging of bESC-like cells on BEF layers, clon margin stem cells gradually merged with the feeder layer and differentiated into fibroblastoid cells whereas colonies the on MEFs showed a clear margin between the stem cells and the feeder layer (Fig. 2). The whole ES cell colonies cultured on MEF layers showed positive $\mathrm{AP}$ staining indicating their stem cell property but only the center of colonies cultured on $\mathrm{BEF}$ s were positive for $\mathrm{AP}$

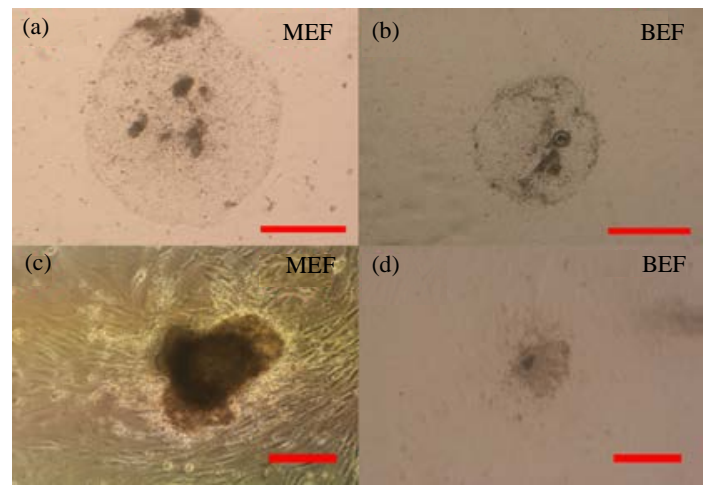

Fig. 1: Morphology of bovine embryonic stem cell-like cells on Mouse Embryonic Fibroblast (MEF) and Bovine Embryonic Fibroblast (BEF) layers. Hatched blastocysts were seeded on MEF or BEF feeder layers. $a, b$ ) Cells from primary colonies and $(\mathrm{c}, \mathrm{d})$ from the 5 th passage are shown (Bar = $500 \mu \mathrm{m})$

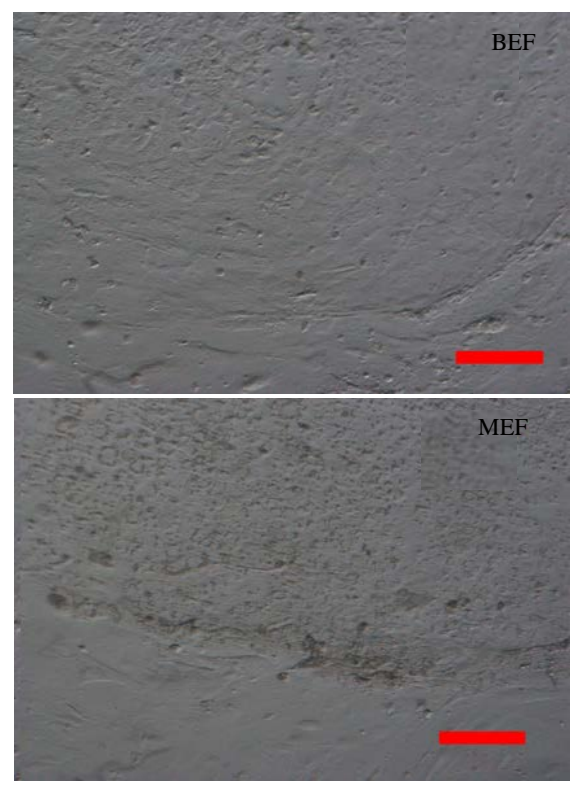

Fig. 2: Morphology of trophoblast stem cells on Mouse Embryonic Fibroblast (MEF) and Bovine Embryonic Fibroblast (BEF) layers. After passaging of bovine embryonic stem cell-like cells, trophoblast stem cells had merged with the BEF feeder layer but there was a clear margin with the $\mathrm{MEF}$ feeder layer $(\mathrm{Bar}=200 \mu \mathrm{m})$

staining and negative at their edges where some colonies showed no AP positive staining within the whole colonies (Fig. 3). These finding indicated that MEF layers worked better than $\mathrm{BEF}$ layers for bESC-like cell isolation and culture. 
Table 1: Effects of feeder layer density on the culture of stem cells

\begin{tabular}{lccccc}
\hline Feeder layer density & Number of embryos & Attachment time (days) & Attachment rate (mean \pm SD) (\%) Primary colony-forming rate (\%) Maximum passage \\
\hline $2 \times 10^{4} / \mathrm{mL}$ & 42 & $3-4$ & $57.0 \pm 1.1^{\mathrm{a}}$ & $11.7 \pm 3.1^{\mathrm{d}}$ & 2 \\
$1.25 \times 10^{5} / \mathrm{mL}$ & 48 & $2-3$ & $77.2 \pm 1.2^{\mathrm{b}}$ & $69.2 \pm 6.7^{\mathrm{e}}$ & 10 \\
$5 \times 10^{5} / \mathrm{mL}$ & 44 & $2-3$ & $68.5 \pm 1.7^{\mathrm{e}}$ & $29.7 \pm 1.8^{\mathrm{f}}$ & 3 \\
\hline
\end{tabular}

There were significant differences among $\mathrm{a}, \mathrm{b}, \mathrm{c}$ and $\mathrm{d}, \mathrm{e}, \mathrm{f}$

Table 2: Effect of embryo management on bovine embry onic stem cell-like cell isolation and culture

\begin{tabular}{lccccc}
\hline Isolation methods & Number of embry os & Attachment time (days) & No. of attachments at day 3 & Attachment rate (mean \pm SD) (\%) & Maximum passage \\
\hline Pronase treatment & 37 & $3-4$ & 10 & $27.1 \pm 3.2^{\mathrm{a}}$ & 2 \\
Naturally hatched & 42 & $2-3$ & 32 & $76.3 \pm 1.6^{\mathrm{b}}$ & 10 \\
Mechanical isolation & 31 & $2-3$ & 26 & $83.9 \pm 3.1^{\mathrm{c}}$ & 1 \\
\hline
\end{tabular}

There was a significant difference among $\mathrm{a}, \mathrm{b}$ and $\mathrm{c}$

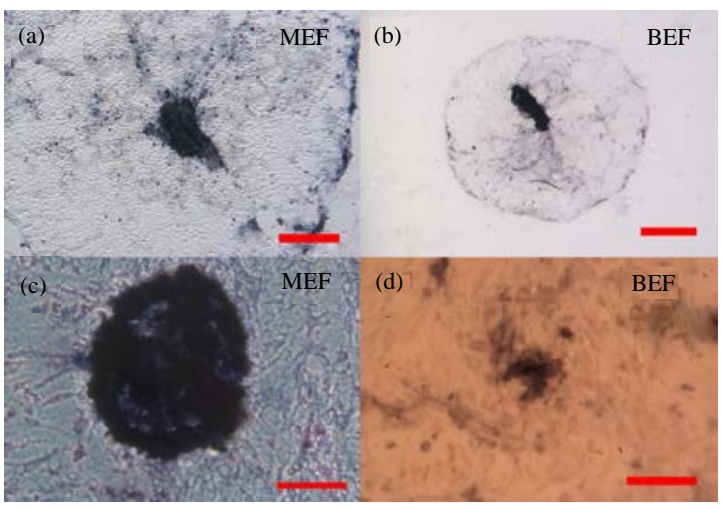

Fig. 3: Alkaline phosphatase staining of bovine embryonic stem cell-like cells on mouse embryonic fibroblast and bovine embryonic fibroblast layers. a, b) Primary culture and c, d) subculture at the fifth passage (a-c Bar $=200 \mu \mathrm{m}$, $\mathrm{d}$ Bar $=500 \mu \mathrm{m})$

Effects of feeder layer density on attachment rate and colony forming rate of embryos: As shown in Table 1, MEFs were more beneficial to the derivation and maintenance of BESC-like cells at a cell density of $1.25 \times 10^{5}$ cells $\mathrm{mL}^{-1}$ as the attachment time for the inner cell mass was shortest, attachment rate highest and primary colony forming rate highest. The attachment rate was significantly lower in the $2 \times 10^{4}$ group than that in the $1.25 \times 10^{5}$ and $5 \times 10^{5} \mathrm{~mL}^{-1}$ groups. It was unfavorable for the maintenance of pluripotency and the colony forming rate was low on this feeder layer at a oncentration of $5 \times 10^{5} \mathrm{~mL}^{-1}$

Effect of embryo treatment on bESC-like cell isolation and culture: Blastocysts subjected to different treatments are shown in Fig. 4. The attachment rate of embryos from which the zona pellucida was removed was $25 \%$ whereas that of embryos that hatched naturally was $76 \%$. The mechanical isolation ICM possessed the highest attachment rate at about $84 \%$ but it could not proliferate and the cells were dark in color. Till the 5th day after
Table 3: Effects of different media on bovine embryonic stem cells

\begin{tabular}{lcccc}
\hline Solution & $\begin{array}{c}\text { Number of } \\
\text { embryos }\end{array}$ & $\begin{array}{c}\text { Attachment rate } \\
(\text { mean } \pm \text { SD) }(\%)\end{array}$ & $\begin{array}{c}\text { Clone formation rate } \\
\text { at third passage (\%) }\end{array}$ & $\begin{array}{c}\text { Maximum } \\
\text { passage }\end{array}$ \\
\hline 1 & 61 & $72.0 \pm 6.3$ & $52.4 \pm 2.3^{\mathrm{a}}$ & 10 \\
2 & 62 & $75.9 \pm 4.3$ & $53.3 \pm 1.5^{\mathrm{a}}$ & 13 \\
3 & 56 & $75.0 \pm 2.8$ & $21.3 \pm 4.2^{\mathrm{b}}$ & 5 \\
\hline
\end{tabular}

The attachment rates of the three groups showed no significant difference $(p>0.05)$; same superscript letters for third passage clone formation rate indicate no significant difference ( $p>0.05$ ), different superscript letters show significant difference $(p<0.01)$

culturing, the cells floated and died (Table 2). The reason for this may be the incomplete removal of zona pellucid or the tight connection of inner cell mass to the zona pellucid so that the stem cell could not be released to attach on feeders for further proliferation. These findings indicate that natural hatching of embryos is beneficial to bESC-like cell isolation and culture.

Effect of culture medium formula on bESC-like cells: Media play crucial role for bESC-like cells maintenance. Here, researchers tested several growth factors and cytokines and found IGF played very important role. There were no significant differences in attachment rate between different media indicating that IGF does not influence embryo attachment. The colonies grew faster with media supplemented with IGF than without IGF. However, the cells were differentiated more and stem cell-like colonies were not form any more at passage five. bESC-like cells in media without IGF could be cultured for $>10$ passages (Table 3 ). In all three solutions, the adherent embryos could form bESC-like colonies; they were tightly packed and there were clear margins between the edges of the colonies and the feeder layers. The primary colonies in Solution 1 were dark in color and the surrounding trophoblast stem cells were loosely arranged and grew slowly. The primary colonies in Solution 2 were less dark and the surrounding trophoblast stem cells were tightly arranged with clear margins between the cells and the feeder layer. The primary colonies in Solution 3 were light in color, the nucleo/cytoplasmic ratio of the surrounding trophoblast stem cells was high and growth was fast (Fig. 5a). After two or three passages, the colonies in all 


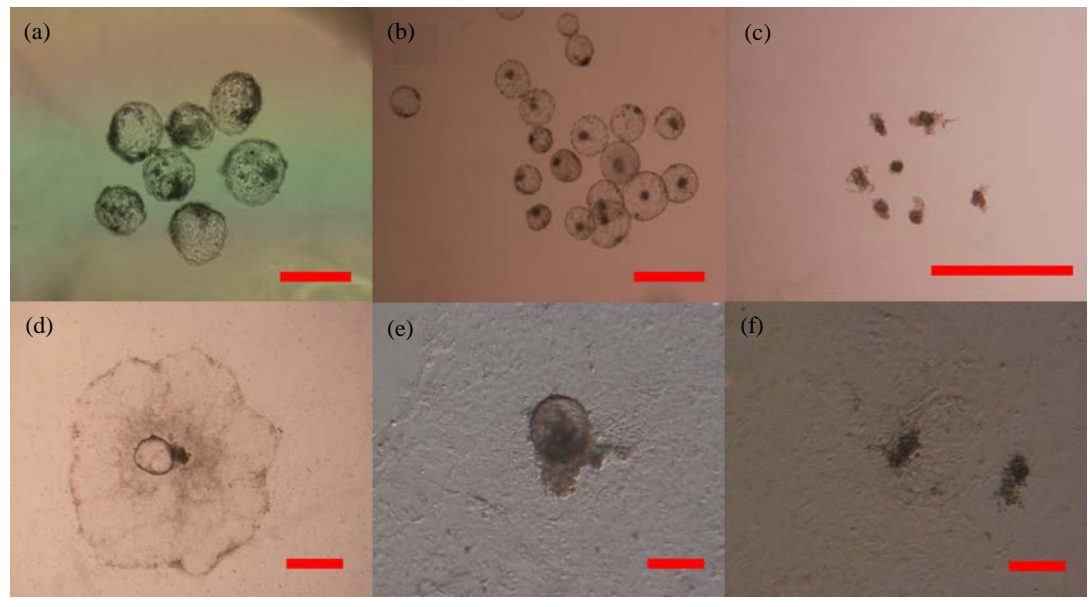

Fig. 4: Effect of embryo management on bovine embryonic stem cell-like cell isolation and culture; a) Embryo from which the zona pellucida had been removed; b) Hatched embryo; c) Inner Cell Mass (ICM); d) Primary colonies from embryo from which the zona pellucida had been removed; e) Primary colonies from hatched embryo; f) Primary colonies from ICM (a-c bar $=500 \mu \mathrm{m}$, d-f bar $=200 \mu \mathrm{m})$

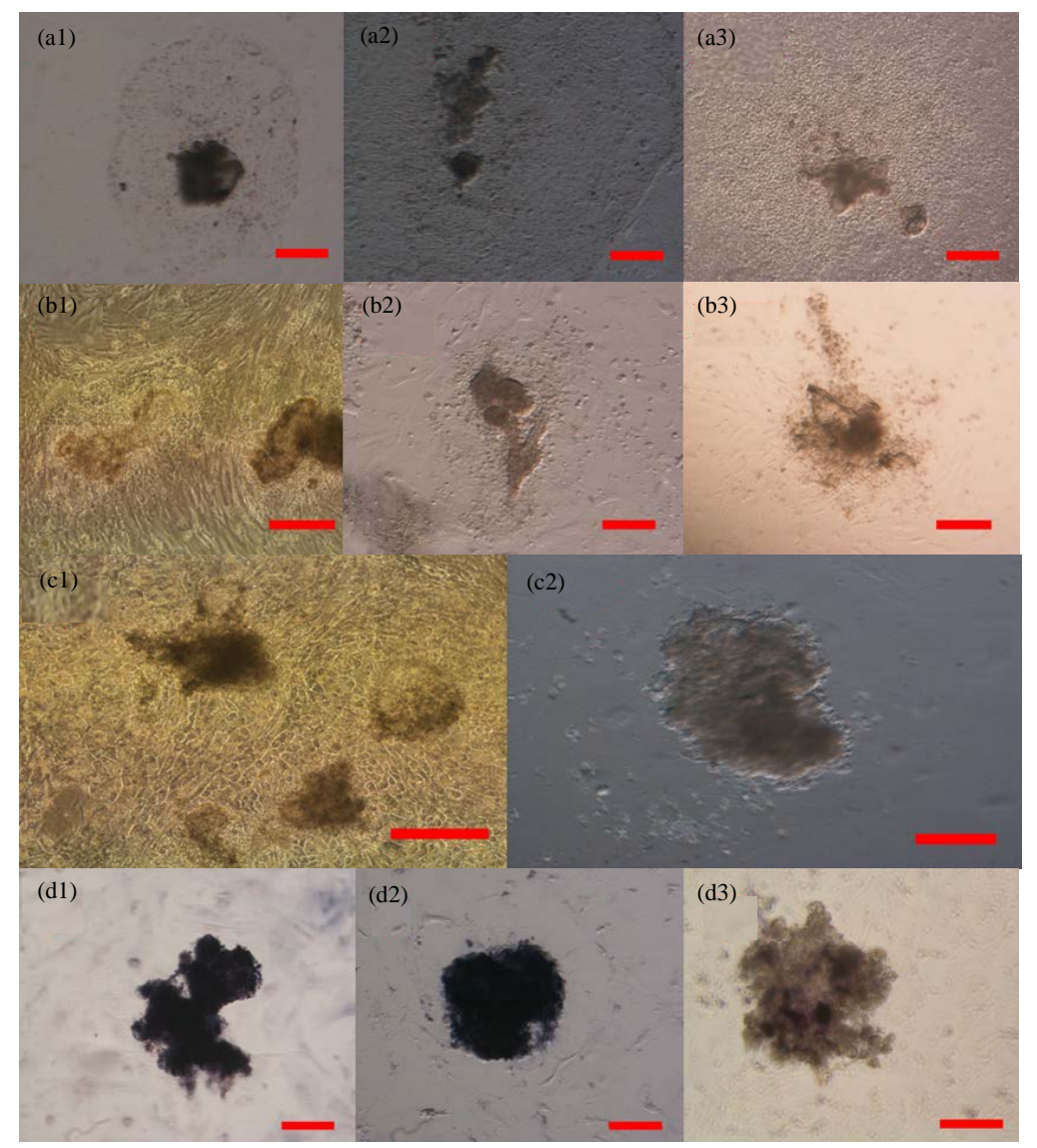

Fig. 5: Morphology of bovine Embryonic Stem Cell (bESC)-like cells in different media. a) bESC-like cells cultured on mouse embryonic fibroblast feeder layers in Solutions 1-3 at 0 passages; b) the 5th passage and c) the 10th passage. Alkaline phosphatase staining of bESC-like cells at the 10th and 5th passages (right) is also shown $(\mathrm{Bar}=200 \mu \mathrm{m})$ 
three solutions were growing faster than the primary culture. After the 3rd passage, the colonies were obviously differentiated. At the 4th day, disaggregated cells at the borders of the colonies were floating and dead. The colonies were not tightly packed and numerous cells were not attached during the next passage. At the 4th day, a few dead cells were floating around the colonies in Solutions 1 and 2. The colonies were tightly packed and mechanically separated colonies and cell mass showed attachment and growth. The cells maintained their pluripotency after 10 passages. By contrast, the colonies in Solution 3 were clearly differentiated at the fifth passage and had lost their pluripotency (Fig. 5b and c). The AP activity in these colonies is shown in Fig. 5d. bESC-like cells were positively stained for AP assay at the 10th passage in Solutions 1 and 2 but only partially positively stained from the 5 th passage in Solution 3 indicating that the cells in Solution 3 had begun to differentiate.

bESC-like cell verification: To confirm that the isolated cells were possessed pluripotent property, we tested the expression of SSEA-1, SSEA-4, TRA-1-60 and OCT-4 in cells at the 5 th passage. As shown in Fig. 6a, the cells

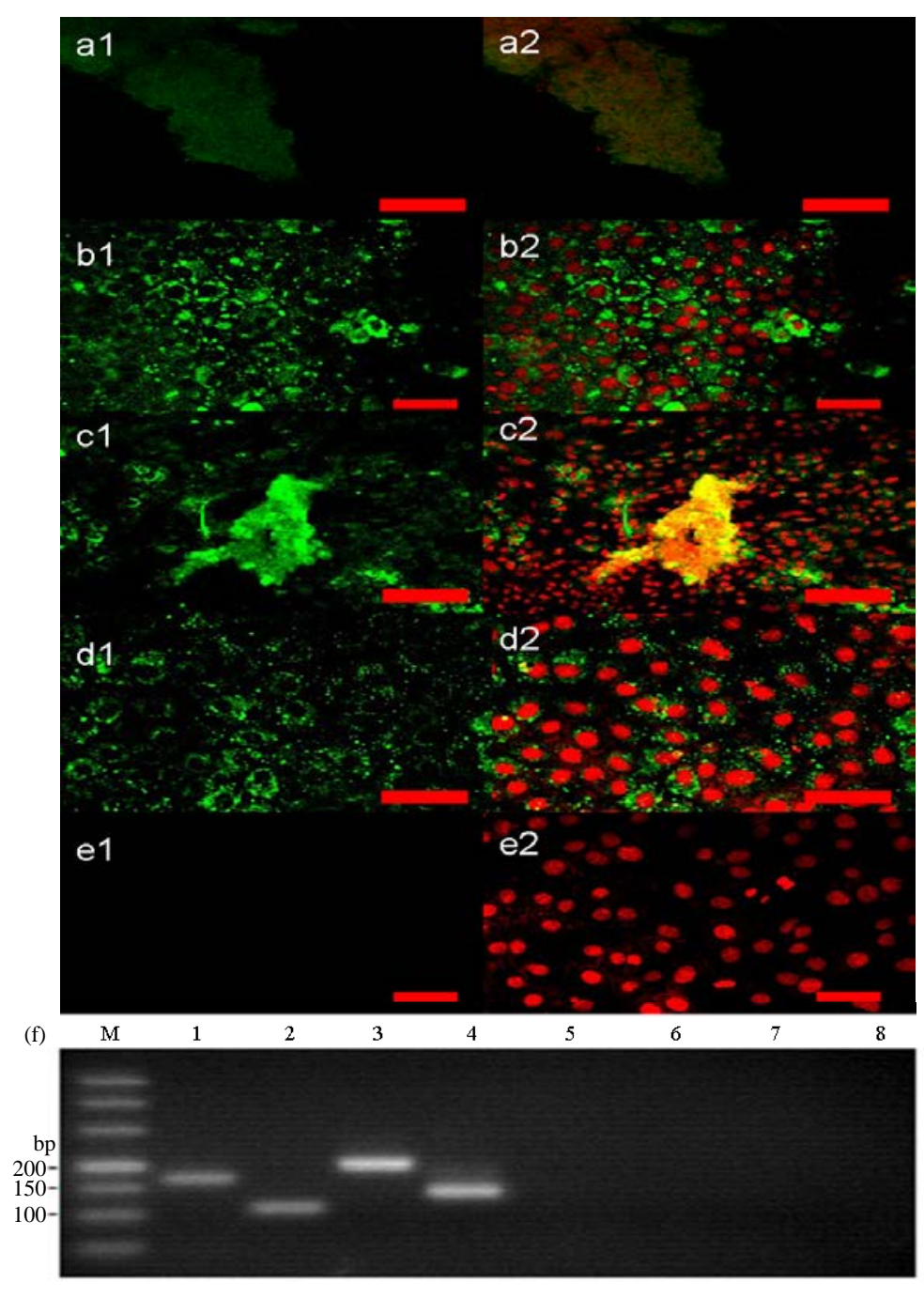

Fig. 6: a) Representative immunofluorescence staining and b) RT-PCR of bovine embryonic stem cell-like cells at the fifth passage. (a) a1: OCT-4; a2: Propidium IODDE (PI)/OCT-4; b1: SSEA-1; b2: PI/SSEA-1; c1: SSEA-4; c2: PI/SSEA-4; d1: TRA-1-61; d2: PI/TRA-1-61; e1 : primary antibody replaced by phosphate buffered saline; e2: PI. f) 1: Nanog; 2: Oct-4; 3: Sox-2; 4: GAPDH; 5: Nanog negative control; 6: Oct-4 negative control; 7: Sox-2 negative control; 8: GAPDH negative control 
clearly expressed these antigens indicating that they were undifferentiated. The cells also expressed Nanog, Oct-4 and Sox-2 indicating that they maintained their pluripotency.

Feeder layer cells are important for the in vitro culture of ES cells being used to assimilate the culture medium, secrete LIF, aFGF, bFGF and other growth factors, improve the growth environment for inoculated cells and inhibit multidirectional differentiation of stem cells. The environment of in vivo embryo implantation is simulated using feeder layers which are conducive to the attachment and growth of embryos and rapid proliferation of the ICM. However, many cell growth factors secreted by the feeder layer not only promote the proliferation of ES cells but also inhibit their differentiation. The micro-environment provided by feeder layers to ES cells is complex; indeed, 136 different proteins have been isolated from conditioned MEF medium (Lim and Bodnar, 2002). Mitogenic factors such as bFGF promote proliferation whereas factors such as LIF inhibit differentiation. It has been demonstrated that MEFs are most suitable for the maintenance of ES cells although, Strojek has suggested that an in vitro culture system using homologous embryonic fibroblasts is closer to the developmental conditions of homologous embryos and achieves better isolation than MEFs (Strojek et al., 1990). In this study, researchers compared the effects of $\mathrm{BEF}$ and $\mathrm{MEF}$ feeder layers on the isolation of bESC-like cells and found that MEFs were more suitable for their isolation and culture, consistent with the findings of Rexroad and Powell (1997).

The density of the feeder layer also influences the culture of ES-like cells. Low-density feeder cells and cell overlay for a long period of culture lead to cell senescence, manifested as a reduction in attachment, nuclear cleavage and vacuolization as well as degeneration of cytoplasmic particles. The gap between cells is too large for adequate provision of nutrients, leading to difficulties with blastocyst attachment, low ICM hatching rates and ES cell differentiation and variation. When the feeder cell density is too high, cell life span is shortened. First, limited nutrients in the culture medium and high cell concentrations result in nutritional deficiencies. Second, the cells generate metabolites that are released into the environment, causing changes in the $\mathrm{pH}$ and other aspects of the medium when their concentrations reach a certain level; the feeder cells are easy to curl off, affecting the growth of the ES cells. The experimental results showed that the best inoculation density of the feeder layer was $1.25 \times 10^{5} \mathrm{~mL}^{-1}$. At this concentration, there were no gaps between cells, no dead cells and good growth and a cell monolayer was formed; this met the needs of proliferating of bovine ES cells, especially early bovine ES cell clones.

Various methods are used to access the ICM such as mechanical picking after whole embryo culture, immunosurgery and enzyme digestion. To culture bovine ES cells, the ICM is obtained by removing the zona pellucida by enzyme digestion or immunosurgery; this method is easier and more efficient than direct natural hatching from the blastocyst. The results of enzyme digestion are better than those of immunosurgery although, stem cells obtained by immunosurgery are not prone to differentiation. However, immunosurgery is cumbersome, improper handling affects the proliferation of the ICM and the cell cloning rate is no higher than that achieved with direct embryo culture. The comparison of three different isolation methods, the results suggest that direct culture of naturally hatched was the most conducive to the isolation and culture of bovine ES cells. The quality of the blastocyst greatly influences the isolation and culture of stem cells. In this study, bovine embryos were obtained by in vitro maturation in vitro fertilization and in vitro development. Blastocyst hatching is a measure of blastocyst quality the fact that blastocysts can be hatched proves their viability.

The growth of bESC-like cells was compared in three different culture media in this study. The previous study indicated that LIF and bFGF are necessary for the culture of bESC-like cells (Wang et al., 2005). IGF-1 has been shown to enhance the synthesis of DNA and proteins in embryonic cells, promote cell division increase embryonic cells and promote the proliferation of trophoblast and ICM (Wang et al., 2007). Therefore, $10 \mathrm{ng} \mathrm{mL}^{-1}$ of IGF-1 was added to Solution 3. Stem cell colonies in this culture system grew significantly faster and the area of clone colonies was larger. However, cell differentiation intensified after five generations and maintaining the characteristics of stem cells was difficult indicating IGF-1 is not beneficial to the maintenance of bESC-like cells.

\section{CONCLUSION}

In this study bESCs could be established under the current culture conditions but their pluripotency and continued proliferation after several passages were not be maintained. Other crucial factors need to maintain the pluripotency of hESCs in the culture conditions.

\section{ACKNOWLEDGEMENTS}

This research was supported by a grant from the National High Technology Research and Development 
Program (863 Program) of China (008AA101005). Appreciation is extended to Dr. Caihong Qiu for her review and comment.

\section{REFERENCES}

Cao, S., F. Wang, Z. Chen, Z. Liu and C. Mei et al., 2009. Isolation and culture of primary bovine embryonic stem cell colonies by a novel method. J. Exp. Zool. A Ecol. Genet. Physiol., 311: 368-376.

Evans, M.J. and M.H. Kaufman, 1981. Estabfishment in culture of pluripotential cells from mouse embryos. Nature, 292: 154-156.

Gjorret, J.O. and P. Maddox-Hyttel, 2005. Attempts towards derivation and establishment of bovine embryonic stem cell-like cultures. Reprod. Fertil. Dev., 17: 113-124.

Imreh, M.P., S. Wolbank, C. Unger, K. Gertow and A. Aints et al., 2004. Culture and expansion of the human embryonic stem cell line HS181, evaluated in a double-color system. Stem Cells Dev., 13: 337-343.

Li, M., W. Ma, Y. Hou, X.F. Sun, Q.Y. Sun and W.H. Wang, 2004. Improved isolation and culture of embryonic stem cells from Chinese miniature pig. J. Reprod. Dev., 50: 237-244.

Lim, J.W. and A. Bodnar, 2002. Proteome analysis of conditioned medium from mouse embryonic fibroblast feeder layers which support the growth of human embryonic stem cells. Proteomics, 2: $1187-1203$.

Mali, P., Z. Ye, H.H. Hommond, X. Yu and J. Lin et al., 2008. Improved efficiency and pace of generating induced pluripotent stem cells from human adult and fetal fibroblasts. Stem Cells, 26: 1998-2005.

Manton, K.J., S. Richards, D. van Lonkhuyzen, L. Cormack, D. Leavesley and Z. Upton, 2010. A chimeric vitronectin: IGF-I protein supports feedercell-free and serum-free culture of human embryonic stem cells. Stem Cells Dev., 19: 1297-2305.

Munoz, M., C. Diez, J.N. Caamano, A. Jouneau, I. Hue and E. Gomez, 2008. Embryonic stem cells in cattle. Reprod. Domest. Anim., 4: 32-37.
Ozolek, J.A., E.P. Jane, L. Krowsoski and P.J. Sammak, 2007. Human embryonic stem cells (HSF-6) show greater proliferation and apoptoses when grown on glioblastoma cells than mouse embryonic fibroblasts at day 19 in culture: comparison of proliferation, survival, and neural differentiation on two different feeder cell types. Stem Cells Dev., 16: 403-412.

Park, S.B., K.R. Yu, J.W. Jung, S.R. Lee and K.H. Roh et al., 2009. bFGF enhances the IGFsmediated pluripotent and differentiation potentials in multipotent stem cells. Growth Factors, 27: 425-437.

Rexroad, C.E. Jr. and A.M. Powell, 1997. Culture of blastomeres from in vitro-matured, fertilized, and cultured bovine embryos. Mol. Reprod. Dev., 48: 238-245.

Roach, M., L. Wang, X. Yang and X.C. Tian, 2006. Bovine embryonic stem cells. Methods Enzymol., 418: 21-37.

Saito, S., B. Liu and K. Yokoyama, 2004. Animal embryonic stem (ES) cells: Self-renewal, pluripotency, transgenesis and nuclear transfer. Hum. Cell, 17: $107-115$.

Sims, M. and N.L.M. First, 1994. Production of calves by transfer of nuclei from cultured inner cell mass cells. Proc. Natl. Acad. Sci. USA., 91: 6143-6147.

Strojek, R.M., M.A. Reed, J.L. Hoover and T.E. Wagner, 1990. A method for cultivating morphologically undifferentiated embryonic stem cells from porine blastocysts. Theriogenology, 33: 901-913.

Sukoyan, M.A., S.Y. Vatolin, A.N. Golubitsa, A.I. Zhelezova, L.A. Semenova and O.L. Serov, 1993. Embryonic stem cells derived from morulae, inner cell mass and blastocysts of mink: Comparisons of their pluripotencies. Mol. Reprod. Dev., 36: 148-158.

Wang, L., E. Duan, L. Sung, B. Jeong, X. Yang and X.C. Tian, 2005. Generation and characterization of pluripotent stem cellsfrom cloned bovine embryos. Biol. Reprod., 73: 149-155.

Wang, L., T.C. Schulz, E.S. Sherrer, D.S. Dauphin and S. Shin et al., 2007. Self-renewal of human embryonic stem cells requires insulin-like growth factor-1 receptor and ERBB2 receptor signaling. Blood, 110: 4111-4119. 